\title{
Sobre la dimensión representacional de la psique según Cornelius Castoriadis
}

\author{
On the representational dimension of the psyche according to Cornelius \\ Castoriadis
}

\section{Germán Rosso*}

Resumen: El presente trabajo se propone recuperar la reflexión filosófica y psicoanalítica de Cornelius Castoriadis para profundizar en la comprensión de la dimensión representacional de la actividad anímica. En el primer apartado se retoma el modo en que este autor se posiciona al respecto de la obra freudiana y sus planteos acerca de la articulación entre psique, representación e imaginación. Luego, se aborda la capacidad primigenia de representación que Castoriadis postula al nivel de la psique, revisitando los problemas de la delegación de la pulsión y la emergencia de las fantasías originarias en la tradición psicoanalítica freudiana. Finalmente, se propone un modo de abordar las alteraciones de esta capacidad representacional como "modos de organización" estratificados, es decir, como capacidades de "puesta en forma" y "puesta en sentido" cualitativamente diferenciables que se instituyen en la subjetividad durante el devenir psicogenético.

Palabras clave: Castoriadis; Representación; Pulsión; Fantasía; Estratificación; Subjetividad

\begin{abstract}
This paper proposes to recover the philosophical and psychoanalytic thought of Cornelius Castoriadis to deepen understanding of the representational dimension of the psychic life. First, I return to the way in which this author positions himself regarding the Freudian work and his ideas about the articulation between psyche, representation and imagination. Then, I address the original capacity of representation that Castoriadis postulates at the level of the psyche, revisiting the problems of the delegation of the drive and the emergence of the primal phantasies in the Freudian psychoanalytic tradition. Finally, I propose a way of understanding the alterations of this representational capacity as stratified "modes of organization", that is, as capacities of "putting into form" and "putting into meaning" qualitatively differentiable that are instituted in subjectivity during the psychogenesis.
\end{abstract}

Keywords: Castoriadis; Representation; Drive; Phantasy; Stratification; Subjectivity

Una de las características sobresalientes y más ricas de la perspectiva freudiana radica en el desarrollo de múltiples puntos de vista en su intento de comprender los procesos psíquicos y sus transformaciones en el decurso de la vida del sujeto. Es así como

\footnotetext{
* Becario doctoral del Instituto de Investigaciones Gino Germani, Facultad de Ciencias Sociales, Universidad de Buenos Aires) por CONICET (Consejo Nacional de Investigaciones Científicas y Técnicas, Buenos Aires, Argentina). E-mail: ger.rosso@hotmail.com ORCID: https://orcid.org/0000-0003-4856-6831
} 
desde un punto de vista económico puede reflexionarse acerca de las mutaciones en la circulación y distribución de una energía psíquica cuantificable (pensada como “magnitudes”, “montos” o “cantidades”), desde una perspectiva tópica se piensa el funcionamiento del "aparato psíquico" diferenciando entre sus distintas "partes” y las "funciones" correspondientes a cada una, y desde un enfoque dinámico se estudia el surgimiento de los conflictos y las tensiones entre las distintas fuerzas que coexisten en la psique, así como los precarios “compromisos” que las mismas logran establecer. Si bien estas perspectivas resultan centrales para comprender los diversos procesos que atraviesan la vida anímica, cabe señalar que en ellas predomina cierta desatención sobre una serie de aspectos más pertinentes a una dimensión cualitativa de los fenómenos psíquicos, que en pocas ocasiones resulta tematizada en sí misma. La utilización del término "fenómeno" aquí no resulta inocente aquí, ya que para comprender lo que hace a las formas y al sentido se requiere de un enfoque fenoménico o fenomenológico gracias al cual pueda pensarse el modo en que las cosas se aparecen o se presentan al sujeto. Aunque diversas categorías desarrolladas por Freud permitirían reflexionar sobre esta problemática, habría que pensar si el peso del cientificismo positivista de su época no le llevó a ponderar, al menos en un primer momento, los aspectos cuantificables y medibles por sobre los aspectos cualitativos inherentes al orden del sentido y de la subjetividad. En esta dirección, las elaboraciones metapsicológicas de la psicoanalista Piera Aulagnier apuntan a indagar la constitución del psiquismo centrándose en su actividad de representación, entendida como la metabolización de elementos heterogéneos de información en elementos homogéneos a los procesos psíquicos. De un modo similar, el filósofo y psicoanalista Cornelius Castoriadis aborda el trabajo de puesta en forma o presentación -de in-formación- fuera del cual, desde su punto de vista, resulta imposible pensar la índole misma de la psique. El presente trabajo se propone recuperar esta serie de aportes para profundizar en la comprensión de la dimensión representacional de la actividad anímica. En el primer apartado se retomará el modo en que Castoriadis se posiciona al respecto de la obra freudiana y sus planteos acerca del vínculo entre psique, representación e imaginación. Luego, se abordará la capacidad primigenia de representación que este autor postula al nivel de la psique, revisitando los problemas de la delegación de la pulsión y la emergencia de las fantasías originarias en la tradición psicoanalítica freudiana. Finalmente, se propondrá un modo de abordar las alteraciones psicogenéticas de esta capacidad representacional como "modos de organización" estratificados, es decir, como capacidades de "puesta en forma" y "puesta en sentido" cualitativamente diferenciables que se sedimentan en la constitución de la subjetividad. 


\section{La aproximación de Castoriadis a Freud: psique, imaginación y representación}

La lectura de Castoriadis sobre la obra freudiana no consiste en la simple utilización o aplicación de sus categorías psicoanalíticas tal cual fueron formuladas; pero a la vez, tampoco puede decirse que se trate de un intento de refundar o reconstruir radicalmente la disciplina, a diferencia de lo que plantea al respecto del pensamiento filosófico heredado. Lo que el autor se propone no es "mejorar ni reconstruir" la concepción freudiana, sino "iluminar[la] de otro modo", partiendo de dos temas que "han sido sus puntos ciegos: el de la institución histórico-social y el de la psique como imaginación radical, es decir, en lo esencial, como emergencia de representaciones o flujo representativo no sometido a la determinidad"1. El primero de estos puntos, que no será profundizado en este trabajo, lleva a Castoriadis a explorar el inextricablemente vínculo entre psicogénesis y sociogénesis, así como también a formular una noción "ampliada” de sublimación ${ }^{2}$, actualmente reconocida en su originalidad dentro del campo del psicoanálisis ${ }^{3}$ y también como un aporte relevante para la filosofía ${ }^{4}$. Al respecto del segundo punto, puede notarse que Castoriadis asocia la cuestión de la psique a la imaginación radical y al surgimiento de las representaciones, a tal punto que llega a afirmar que "la índole misma de la psique [...] es génesis de representaciones" ${ }^{5}$. Tal como plantea Urribarri ${ }^{6}$, este énfasis en la dimensión representacional tendrá importantes consecuencias en su elucidación acerca del modo de ser de la psique, llevándolo a modificar y radicalizar nociones freudianas como las de inconsciente, afecto y placer, entre otras. Sin embargo, hay que evaluar en su justa medida la novedad de este abordaje, ya que en primera instancia se puede señalar que el vínculo fundamental entre psique y representación es claramente establecido por Freud, sobre todo tras abandonar el modelo preponderantemente fisiológico y neuronal del Proyecto de psicología de 1895 y comenzar progresivamente a centrarse en los aspectos pertinentes a su metapsicología. Lo que Castoriadis particularmente se propondrá buscar en esta relación establecida por el psicoanálisis es el fundamento de su idea de imaginación, potencia que desde su punto de vista la propia noción freudiana de representación psíquica a la vez supondría y recubriría.

Si se revisa la obra de Freud puede constatarse que en algunos aspectos este autor continúa siendo deudor de las concepciones modernas de la representación que la fijan en un terreno segundo respecto de una realidad pretendidamente externa, independiente y

\footnotetext{
${ }^{1}$ CASTORIADIS, La institución imaginaria de la sociedad, 430.

${ }^{2}$ Véase CASTORIADIS, Figuras de lo pensable, 251-253. URRIBARRI, Castoriadis: the Radical Imagination and the Post-Lacanian Unconscious. URRIBARRI, Castoriadis: la sublimación extendida.

${ }^{3}$ ROUDINESCO y PLON, Diccionario de psicoanálisis, 1052.

${ }^{4}$ GOURGOURIS, Philosophy and Sublimation.

${ }^{5}$ CASTORIADIS, La institución imaginaria de la sociedad, 433.

${ }^{6}$ URRIBARRI, Castoriadis: the Radical Imagination and the Post-Lacanian Unconscious.
} 
determinante. Tal como señalan Laplanche y Pontalis ${ }^{7}$, el abordaje de Freud sobre este término se mantiene conforme al pensamiento filosófico de su época, por lo que su acepción, más allá del uso original que le brinda, no es modificada. Esto queda claro en los casos en que Freud sostiene que las fantasías "son establecidas por medio de las cosas que fueron oídas (...) combinan lo vivenciado y lo oído, lo pasado (de la historia de los padres y antepasados) con lo visto por uno mismo. Ellas son a lo oído como los sueños son a lo visto"; y también: "las fantasías se generan por una conjunción inconciente entre vivencias y cosas oídas (...). La formación de fantasías acontece por combinación y desfiguración, análogamente a la descomposición de un cuerpo químico que se combina con otro". La fantasía, al fin y al cabo, sólo puede ser pensada como mera reproducción, deformación o a lo sumo recombinación de elementos proporcionados por la percepción. Pero la cuestión es radicalmente distinta a partir de la conocida sentencia del autor en su correspondencia a Fliess de 1897: la confesión con la que comienza esta comunicación, "ya no creo más en mi "neurótica"” 10 , marca un viraje en relación al lugar de las producciones fantásticas de sus pacientes. Es a partir de este giro que Freud podrá dar forma a nociones como las de "fantasías originarias", “representaciones inconscientes” y "realidad psíquica”, fundamentales para el planteo de Castoriadis. Partiendo de esta última noción, se puede pensar que las fantasías del neurótico también "poseen una suerte de realidad”, en el sentido de que poseen la misma fuerza que las vivencias reales o, dicho de otro modo, son vivenciadas como si fuesen reales: "Ellas poseen realidad psíquica, por oposición a una realidad material, y poco a poco aprendemos a comprender que en el mundo de las neurosis la realidad psíquica es la decisiva"11. Todo esto se desprende de "la intelección cierta de que en lo inconciente no existe un signo de realidad, de suerte que no se puede distinguir la verdad de la ficción investida con afecto"12. Las representaciones inconscientes, por su parte, se caracterizan por ser eficientes aún a pesar de que la conciencia del sujeto "no tiene noticia alguna de esta idea" ${ }^{13}$. De por sí, esto constituye una crítica fundamental al paradigma filosófico clásico, según el cual toda representación, por su definición misma, pertenece al terreno de la conciencia. Castoriadis leerá en esta ruptura el gesto fundamental de reconocer la existencia de un no-ser, estableciendo así una distancia respecto del pensamiento ontológico heredado que reduce el ser a la categoría de determinación ${ }^{14}$. Por último, la noción de "fantasías originarias" da cuenta, por su parte, de un conjunto de estructuras fantaseadas de carácter típico que no pueden ser remontadas a

\footnotetext{
${ }^{7}$ LAPLANCHE y PONTALIS, Diccionario de psicoanálisis, 367.

${ }^{8}$ FREUD, Fragmentos de la correspondencia con Fliess, 289.

${ }^{9}$ FREUD, Fragmentos de la correspondencia con Fliess, 293.

${ }^{10}$ FREUD, Fragmentos de la correspondencia con Fliess, 301.

${ }^{11}$ FREUD, 23ํㅡㄹ conferencia. Los caminos de la formación de síntoma, 336.

${ }^{12}$ FREUD, Fragmentos de la correspondencia con Fliess, 301-302.

${ }^{13}$ FREUD, Nota sobre el concepto de lo inconciente en psicoanálisis, 273.

${ }^{14}$ CASTORIADIS, La institución imaginaria de la sociedad, 457.
} 
la experiencia vivida de los individuos, aunque la potencia de esta idea será rápidamente recubierta en Freud por una explicación filogenética que intenta dar cuenta de un origen "real" de su contenido ${ }^{15}$.

Sirviéndose de estas ideas Castoriadis planteará que la representación no es el reflejo de una cosa que se hallaría en el "exterior" -dotada de forma independientemente del sujeto- ni puede ser derivada de la percepción sino que consiste en una auténtica presentación -una puesta en forma por parte del sujeto, una in-formación. Aquí comienza a vislumbrarse el vínculo entre representación e imaginación, dado que esta última es la capacidad que hace aparecer las cosas ante el sujeto, la potencia que dota de una forma adecuada a lo que de otro modo no la poseería, y que crea esta forma ex nihilo. Para Castoriadis es justamente en la dimensión psíquica donde se manifiesta más radicalmente esta potencia, ya que desde los albores de la vida subjetiva la psique deberá poner en forma todo lo que se (le) presente, como se verá en detalle en la siguiente sección. Es así como el autor llega a afirmar que "tal vez lo esencial de la obra de Freud resida en el descubrimiento del elemento imaginario de la psique", lo cual se corresponde con las “dimensiones más profundas" de la imaginación radicall'. Pero al mismo tiempo es importante tener en cuenta las tensiones que reviste su interpretación de la obra freudiana, que pueden encontrarse condensadas, por ejemplo, en este tipo de advertencias, formuladas en diversas ocasiones: "Freud, quien, desde el comienzo hasta el fin de su trabajo, no habla de hecho más que de la imaginación, de sus obras y de sus efectos, se niega con obstinación a tematizar este elemento de la psique" ${ }^{17}$. Es así que Castoriadis deberá realizar una lectura a contrapelo sobre los planteos freudianos para lograr detectar los puntos en los que la psique exhibe su intrínseca ligazón con la cuestión de la emergencia de las representaciones, es decir, con la imaginación.

\section{Psique, cualidad y sentido: pulsión y capacidad de representación}

Como se señaló anteriormente, Castoriadis detecta en los planteos de Freud un aporte fundamental en la dirección del descubrimiento del "elemento imaginario" que define al sujeto humano, pero que sin embargo resulta en diversas ocasiones negado y recubierto por el propio autor. Se trata de una situación análoga a los reiterados movimientos de descubrimiento y encubrimiento que Castoriadis ${ }^{18}$ identifica en el trascurso de la historia de la filosofía, en gran medida debido al temor de cimentar el

\footnotetext{
${ }^{15}$ LAPLANCHE y PONTALIS, Fantasía originaria, fantasía de los orígenes, origen de la fantasía.

${ }^{16}$ CASTORIADIS, La institución imaginaria de la sociedad, 441.

${ }^{17}$ CASTORIADIS, Lógica, imaginación, reflexión, 24.

${ }^{18}$ CASTORIADIS, Hecho y por hacer. Pensar la imaginación. CASTORIADIS, Los dominios del hombre. Las encrucijadas del laberinto.
} 
edificio del conocimiento sobre un suelo en apariencia tan lábil como el de la imaginación. En el caso del pensamiento psicoanalítico de Freud, Castoriadis reconoce en él una de las principales "vías" para llegar a la idea del imaginario radical, sobre todo en lo que refiere a la dimensión singular de la imaginación del sujeto ${ }^{19}$. Sin embargo, es necesario asumir desde un inicio que, para Castoriadis, la reflexión de Freud constituye un aporte "profundamente antinómico" 20 , pues al mismo tiempo que en sus trabajos "no habla de hecho más que de la imaginación, de sus obras y de sus efectos" ${ }^{21}$, también "se puede decir que una gran parte de su obra apunta o conduce inexorablemente a reducir, recubrir y ocultar nuevamente este papel [imaginario que podría atribuirse a la psique]"22. Es aquí donde puede detectarse la pregnancia de cierto espíritu de época en la obra de Freud, como tantas veces se ha dicho al respecto de sus intenciones positivistas y cientificistas, lo cual también suele ser explicado por su formación previa como médico neurólogo. Esta pregnancia también se podría vincular con la perpetuación de los esquemas ontológicos heredados y su necesidad de reducir, ignorar o negar el rol de la imaginación. Castoriadis ${ }^{23}$ detecta principalmente estos resabios en la insistencia continua de Freud de hallar los "factores reales" que expliquen en último término el acontecer anímico de los individuos: desde la creencia en la realidad efectiva del acontecimiento traumático, hasta las diversas reformulaciones, avances y claudicaciones en esta cuestión que lo llevaron a sostener que ese acontecimiento real podría reconstruirse por la vía filogenética, lo que hay en Freud es el establecimiento de un causalismo que va de lo real a lo psíquico.

A pesar de estas erratas positivistas, Castoriadis afirma que el descubrimiento freudiano de la imaginación puede localizarse en "la importancia capital de la fantasía en la psique y la relativa independencia y autonomía de la producción de fantasías", elementos que permitirían pensar en una actividad de la imaginación "aun cuando ésta no se reconozca ni se nombre" 24 . Lo que resulta central para elucidar el carácter imaginario de la psique es el sitio que la fantasía ocupa respecto de la cuestión del surgimiento u origen de las representaciones psíquicas. Para abordar este tema, Castoriadis recupera en primer lugar el problema de la manifestación de las pulsiones en el terreno psíquico. Cabe tener en cuenta que la noción de pulsión ocupa en el pensamiento freudiano un lugar cuanto menos ambiguo. En "Pulsiones y destinos de pulsión” (1915), principal texto dedicado a esta cuestión, Freud la define como "un concepto fronterizo entre lo anímico y lo somático, como un representante psíquico de los estímulos que provienen del interior del

\footnotetext{
${ }^{19}$ CASTORIADIS, Hecho y por hacer. Pensar la imaginación.

${ }^{20}$ CASTORIADIS, Hecho y por hacer. Pensar la imaginación, 288.

${ }^{21}$ CASTORIADIS, Lógica, imaginación, reflexión, 24.

22 CASTORIADIS, La institución imaginaria de la sociedad, 441.

${ }^{23}$ CASTORIADIS, La institución imaginaria de la sociedad, 441-442.

${ }^{24}$ CASTORIADIS, La institución imaginaria de la sociedad, 442.
} 
cuerpo y alcanzan el alma”25. De esta manera podría pensarse que la pulsión se encuentra asentada en el terreno psíquico o, como propone Strachey, que "Freud no trazaba distinción alguna entre una pulsión y su 'agencia psíquica”" ${ }^{26}$. Otros escritos de Freud establecerán una distinción más nítida entre la pulsión propiamente dicha, que resultaría pertinente al orden somático, y su "representante”, elemento exclusivamente psíquico. Tal es el caso del texto "Lo inconciente" (1915), oportunidad en la que Freud establece con mayor claridad este nuevo ordenamiento: "Una pulsión nunca puede pasar a ser objeto de la conciencia; sólo puede serlo la representación que es su representante. Ahora bien, tampoco en el interior de lo inconsciente puede estar representada si no es por la representación”27. Aquí es la pulsión en sí misma la que es considerada como estrictamente ajena al terreno psíquico. Pero como señala Strachey tras recorrer estas vacilaciones, puede que esta contradicción sea "más aparente que real" y que en todo caso ayude a destacar "la ambigüedad del concepto mismo", que se debe justamente a su carácter fronterizo entre el orden psíquico y el somático ${ }^{28}$. Finalmente puede decirse que, se encuentre la pulsión a un lado o al otro de la frontera de la psique, lo que queda claro es que en los planteos de Freud las fuerzas o estímulos provenientes del interior del cuerpo necesitarán de un "representante”, de una “delegación” como apunta Laplanche ${ }^{29}$, que le permita manifestarse en (o ante) la psique. Es en la emergencia de este "delegado" o "representante" donde puede detectarse el "trabajo creador" de la psique gracias al cual ella podrá presentarse algo proveniente de un orden ajeno ${ }^{30}$. De aquí que Castoriadis establezca que "para la psique nada puede existir si no es en el modo de la representación" 31 , o de manera más precisa, que "la psique es ella misma emergencia de representaciones acompañadas de un afecto e insertas en un proceso intencional”32.

Es interesante agregar al respecto de esta cuestión que Castoriadis señala como arquetipo de la delegación de la pulsión por representación a ciertos desarrollos primigenios del Proyecto de psicología de 1895. Una de las temáticas que allí se abordan es la capacidad de la psique de “crear imágenes y relacionarlas a partir de 'estímulos' que no tienen ninguna relación cualitativa con esas imágenes" ${ }^{33}$. De lo que se trata aquí es de un nivel que en sí mismo la psique humana comparte con todo lo viviente -razón por la cual Castoriadis señala que "supera ampliamente el terreno psicoanalítico", lo que a su vez

\footnotetext{
${ }^{25}$ FREUD, Pulsiones y destinos de pulsión, 117.

${ }^{26}$ STRACHEY, Nota introductoria a "Pulsiones y destinos de pulsión”, 108.

${ }^{27}$ FREUD, Lo inconciente, 173.

${ }^{28}$ STRACHEY, Nota introductoria a “Pulsiones y destinos de pulsión”, 108.

${ }^{29}$ LAPLANCHE, La sublimación (Problemáticas III), 45-46.

${ }^{30}$ CASTORIADIS, Hecho y por hacer. Pensar la imaginación, 296.

${ }^{31}$ CASTORIADIS, La institución imaginaria de la sociedad, 457.

32 CASTORIADIS, La institución imaginaria de la sociedad, 442.

${ }^{33}$ CASTORIADIS, Lógica, imaginación, reflexión, 29.
} 
podría explicar por qué Freud abandona este terreno posteriormente-, y que refiere a la transformación de "masas de materia y energía” externas (que serían de un orden cuantitativo) en cualidades, es decir, en formas ${ }^{34}$. Este nivel sería compartido con lo viviente en la medida en que refiere a la imaginación en su máxima generalidad, como la creación de un mundo propio que todo para sí deberá realizar para cumplir con sus autofinalidades ${ }^{35}$. En cambio, Castoriadis comprende que la cuestión del origen de la representación de las pulsiones hace a un nivel "mucho más específico del psicoanálisis", aunque en cierta medida retoma y reformula el problema anteriormente mencionado: se recupera "la relación entre la cantidad (física) y la cualidad (psíquica), transformándolo en [el] problema de la relación entre lo somático y lo psíquico" ${ }^{36}$. Pero tanto en uno como en otro caso, así como también se podría decir respecto de los sueños, lo que insiste es el "permanente y obligatorio trabajo de la psique para darle figurabilidad a algo que en sí mismo no tiene figura para la psique" ${ }^{37}$. En el caso que aquí interesa, el de las pulsiones, se puede decir con Castoriadis que

provenientes (...) de los trasfondos de la organización y el funcionamiento somáticos, las pulsiones deben actuar sobre el psiquismo, pese a no tener (precisamente) cualidad psíquica. Para adquirir una especie de existencia para la psique, tienen que devenir presentes para ella, serle presentadas vale decir representadas, encontrar un representante, un delegado, un embajador, un portavoz (...). Pero para la psique no existe nada que no sea representación, Vorstellung ${ }^{38}$.

En torno a esta cuestión surge toda una serie de metáforas habilitadas por la traducción del término alemán Repräsentanz, las cuales refieren a la necesidad de que la pulsión envíe a la psique “embajadores”, “representantes”, “delegados”, los cuales, como señala Castoriadis, "para hacerse entender deben hablar un lenguaje reconocible y 'comprensible' por lo psíquico - por eso tienen que presentarse como representaciones" 39. Y aunque el término "representación” (Vorstellung), como apunta Laplanche, tenga en

${ }^{34}$ CASTORIADIS, Hecho y por hacer. Pensar la imaginación, 297-298.

${ }^{35} \mathrm{Al}$ respecto de la perspectiva ontológica elaborada por Castoriadis a partir de la década de 1980, véase ADAMS, Castoriadis and autopoiesis. Tal como plantea esta autora, Castoriadis recupera elementos de perspectivas contemporáneas sobre la autopoiesis como la de Matura y Varela así como también del antiguo pensamiento griego, en particular de los filósofos pre-socráticos. De este modo establece tres características centrales del para sí: autofinalidad, creación de un mundo propio y autocentramiento. En base a ellas propone distinguir cuatro niveles ontológicos: lo viviente, lo psíquico, el individuo social y la sociedad. Otros dos niveles del para sí existen en carácter de proyecto: la subjetividad humana y la sociedad autónoma. Véase en particular CASTORIADIS, El estado del sujeto hoy.

${ }^{36}$ CASTORIADIS, Lógica, imaginación, reflexión, 29.

${ }^{37}$ CASTORIADIS, Hecho y por hacer. Pensar la imaginación, 298.

${ }^{38}$ CASTORIADIS, Hecho y por hacer. Pensar la imaginación, 298.

${ }^{39}$ CASTORIADIS, Hecho y por hacer. Pensar la imaginación, 299. 
alemán una raíz completamente distinta a la de esta acción de representación en cuanto delegación (Repräsentieren), ambos términos se reencuentran cuando se comprende cómo debe ser ese "embajador" enviado a la psique: Vorstellungsrepräsentant, que Laplanche, en contraposición a Lacan, traduce como "representante de representación”, "representante representativo" o "representante-representación" ${ }^{40}$; y en un sentido cercano, Vorstellungsrepräsentanz des Triebes, que Castoriadis comprende como "delegación de la pulsión (en o ante la psique) por medio de una representación" ${ }^{41}$. De manera que, para concluir con esta cuestión, se puede decir que algo que fue "un empuje de origen somático (...) debe transformarse en algo representable por y para la psique. Tiene que encontrar una representación, una Vorstellung, para ser representado -vertritt- en la psique" ${ }^{42}$.

La consecuencia más importante de estas reflexiones para Castoriadis será la necesidad de reconocer en la psique, desde un inicio, una capacidad de llevar a cabo ese “trabajo creador", de proveerse "representantes” adecuados, es decir, de presentarse e introducir al terreno de la cualidady de la "representación" eso que se encuentra por fuera del mismo. Es por esto que el autor postula que la psique debe necesariamente ser comprendida como “capacidad para hacer surgir una 'primera' representación, una puesta en imagen (Bildung y Einbildung)" 43 . Junto con esto surge el problema de pensar la procedencia de los “materiales" y de la "organización” que involucra esta primera representación, lo cual no solamente resulta pertinente a la elucidación psicoanalítica sobre las etapas más tempranas de la actividad anímica, sino que también plantea un desafío para la filosofía y particularmente para la reflexión sobre el sujeto y su capacidad de organizar el mundo.

En este punto de su argumento, Castoriadis ${ }^{44}$ discute tanto con un enfoque empirista, que sostiene que los elementos de los que se sirve la psique para organizar su primera representación provienen de lo "real" o de la "experiencia", como con su variante "gradualista", que plantea que es gracias a una acumulación paulatina de "experiencias" previas que la psique logra adquirir su capacidad de elaboración. Pero tanto en uno como en otro caso se elide explicar de qué modo resulta posible que elementos provenientes de la "realidad" o de las "experiencias" sean aprehendidos por un sujeto del que se presume que aún no posee la capacidad de presentarlos y organizarlos ante sí mismo. Dicho en otros términos, lo que estas posturas plantean es que aquello que aún no posee una "forma" o “cualidad" psíquica sería capaz de proveer el material y la organización a partir de las cuales se le podría otorgar una. De modo que desde esta óptica se coloca a la psique en una posición pasiva, como si se tratara de un receptáculo abierto a una inculcación mecánica

\footnotetext{
${ }^{40}$ LAPLANCHE, La sublimación (Problemáticas III), 46.

${ }^{41}$ CASTORIADIS, Hecho y por hacer. Pensar la imaginación, 299.

${ }^{42}$ CASTORIADIS, Hecho y por hacer. Pensar la imaginación, 298.

${ }^{43}$ CASTORIADIS, La institución imaginaria de la sociedad, 443.

${ }^{44}$ CASTORIADIS, La institución imaginaria de la sociedad, 443-444.
} 
por la "experiencia", o cuanto mucho se le asignaría un rol de reproductora sin modificaciones de lo "real". Pero Castoriadis es taxativo en esta cuestión: "Si el sujeto no es primero capacidad formante, nada de afuera puede serle otorgado, ni prestado" 45 . Por lo tanto, sin esta "capacidad formante" siquiera podría haber “experiencia”. Es en este sentido que "la creación de un mundo propio precede necesariamente a cualquier 'lección' que los acontecimientos de ese mundo puedan dar" ${ }^{46}$. El sujeto humano es, desde un primer momento, capacidad creadora, y en este sentido es una potencia imaginante:

la psique es un elemento formativo que sólo existe en y por lo que forma $y$ cómo lo forma; es Bildung y Einbildung -formación e imaginación-, es imaginación radical que hace surgir ya una 'primera' representación a partir de una nada de representación, es decir, a partir de nada ${ }^{47}$.

En esta capacidad de hacer emerger representaciones reside el elemento imaginario de la psique, factor implícito en los planteos de Freud pero que al ser expuesto permite comprender que la psique crea, por sus propios medios y sin responder linealmente a una determinación externa, representaciones ex nihilo y según sus propios modos de organización. Ambos aspectos, puesta en forma y organización, resultan inseparables, como se explicará más adelante. Pero lo que además no logran explicar posicionamientos como los recién revisados es de dónde provienen algunos elementos organizativos de las representaciones primigenias que no se encuentran en lo "real”, y que por lo tanto jamás podrían ser provistos por la "experiencia”. Justamente esto es lo que sucede, como se verá a continuación, con la fantasía, que si bien muchas veces es elaborada con materiales provistos por la experiencia, su forma de organizarlos es enteramente ajena a lo "real".

\section{La fantasía como primer momento en la actividad representacional de la psique}

Como se dijo anteriormente, una de las cuestiones abordadas por Freud en las que se puede observar con mayor claridad el trabajo de la capacidad imaginativa de la psique es en la fantasía. A partir de su indagación también se pueden comenzar a vislumbrar algunas de las características específicas de la primera representación que hace emerger la psique. Si bien se podría decir que el "fantasear" es una actividad contemporánea al individuo socializado, a Castoriadis le interesará recuperar su modo de funcionamiento y su organización debido a que se encuentra enraizada en los momentos más primigenios de la actividad psíquica. Esto resulta claro en los planteos de Freud, donde tanto el "fantasear"

\footnotetext{
${ }^{45}$ CASTORIADIS, Sujeto y Verdad en el mundo histórico-social, 68.

${ }^{46}$ CASTORIADIS, Hecho y por hacer. Pensar la imaginación, 302.

${ }^{47}$ CASTORIADIS, La institución imaginaria de la sociedad, 444.
} 
como los "sueños diurnos" son considerados una escisión en la "actividad del pensar" 48 que se genera a partir del establecimiento del "principio de realidad" 49 . A pesar de la entrada en vigencia de este último principio, según Freud la actividad de fantasear "se mantuvo apartada del examen de realidad y permaneció sometida únicamente al principio de placer" ${ }^{50}$, que sería la dinámica que con anterioridad gobernaba la actividad psíquica. De aquí Castoriadis extrae la idea, presente en diversas zonas de la obra de Freud, de que si esa actividad del pensamiento “se mantuvo apartada" respecto de la realidad, evidentemente ya era ajena a esta última anteriormente a su establecimiento: "la implicación es obviamente que el funcionamiento psíquico inicial era puro fantaseo que satisfacía únicamente al principio de placer, o sea imaginación libre" ${ }^{51}$. En esa etapa más primaria de la que darían cuenta el fantasear y los sueños diurnos, entonces, la psique se encuentra sometida enteramente al principio de placer, lo que significa que el surgimiento de representaciones es gobernado exclusivamente por la evitación del displacer y la búsqueda del placer. Si bien esta idea refiere fundamentalmente a uno de los principios económicos que regula el funcionamiento anímico, ya que establece la descarga inmediata de las cantidades excedentes de excitación, se puede plantear que el mismo se corresponde con una actividad representacional bien particular que es la alucinación. En la perspectiva de Freud la alucinación suele ser comprendida como una primera respuesta a las exigencias pulsionales:

el estado de reposo psíquico fue perturbado inicialmente por las imperiosas exigencias de las necesidades internas. En ese caso, lo pensado (lo deseado) fue puesto de manera simplemente alucinatoria, como todavía hoy nos acontece todas las noches con nuestros pensamientos oníricos ${ }^{52}$.

Aunque es interesante notar cómo en esta cita Freud refiere casi explícitamente a una "puesta" de representaciones por parte de la psique, es sin embargo necesario cotejar las implicancias del modelo en el que se basa la noción de alucinación.

Para Castoriadis ${ }^{53}$ el término "alucinación" guarda cierta referencia "aparente y paradójica” a lo "real”, en la medida en que consiste en la recreación de una experiencia placentera anterior que ahora se encuentra ausente. En Freud esto resulta evidente, ya que para él la alucinación por excelencia del infans es la presencia del pecho materno. Aquí la alucinación tomaría prestados -reproduciría- elementos provenientes de una percepción

\footnotetext{
institución imaginaria de la sociedad, 457.

${ }^{49}$ FREUD, Formulaciones sobre los dos principios del acaecer psíquico, 227.

${ }^{50}$ FREUD, Formulaciones sobre los dos principios del acaecer psíquico, 227.

${ }^{51}$ CASTORIADIS, Hecho y por hacer. Pensar la imaginación, 301.

${ }^{52}$ FREUD, Formulaciones sobre los dos principios del acaecer psíquico, 224.

${ }^{53}$ CASTORIADIS, La institución imaginaria de la sociedad, 445.
}

${ }^{48}$ Aquí, "pensar" o "pensamiento” no debe ser entendido bajo el sentido habitual que se le da a la expresión, sino como el propio representar o la vinculación de las representaciones. Véase CASTORIADIS, La 
que en su origen es "real", modelo que se ha replicado también en la comprensión de la fantasía (incluso con las más “originarias”) y de la imaginación, volviendo así a supeditarlas a la mera recreación de una primera experiencia "real”. Resultaría interesante cuestionarse, respecto de la anterior cita de Freud, si lo que la alucinación pone es la representación de una percepción ahora ausente o si es ese "estado de reposo psíquico" que fue perturbado por el empuje de las pulsiones. En la medida en que efectivamente se trate de un "estado" de la psique, puede decirse que necesariamente una representación deberá acompañarlo, ya que como se estableció anteriormente todo lo pertinente a la psique debe obligatoriamente poseer el estatuto de una representación ${ }^{54}$. Esto implicaría sostener que a ese "estado" inicial de reposo le corresponde una representación que es incluso anterior a las "exigencias de las necesidades internas", de modo que antecede a la presentación de las pulsiones por medio de un "delegado" representacional. En todo caso, estas "necesidades internas" significarán la "ruptura” y el "cuestionamiento" de esta primera representación psíquica que se corresponde con el "estado de reposo" 55 . De esta manera no sólo se ve redefinida la actividad alucinatoria -ya no como la reposición de un objeto "real" ausente sino como el intento de reponer un estado representacional previosino que también se comienza a vislumbrar un nivel aun anterior al del imperio del principio de placer o de los procesos primarios. Castoriadis se propondrá emprender la “exploración de este nivel originario”, el cual mayoritariamente resultó evadido por la reflexión psicoanalítica o simplemente reconducido a lo "real" 56.

A partir de una indagación realizada por Laplanche y Pontalis ${ }^{57}$ acerca de la noción de "fantasía originaria" en la obra de Freud, Castoriadis recupera algunas de las características que corresponderían al mencionado nivel originario, aunque señalando que estos autores "no han tematizado ni explotado lo suficiente" 58 algunos de sus importantes hallazgos. Lo que Castoriadis particularmente recupera es un rasgo de las fantasías que insiste aun en aquellas que se basan en una gran cantidad de elementos representativos de carácter secundario, es decir, provenientes de experiencias tardías del sujeto. Ese rasgo consiste en una "huella de arcaísmo" 59 que remite a un estado previo, y que Castoriadis reconoce en el modo en que el sujeto se figura en la fantasía, "sin un lugar que le pueda ser específicamente asignado" 60 . Esto quiere decir que por más que los “escenarios”, los “contenidos", los "personajes" o los “actos” que se despliegan en la fantasía sean productos de una "experiencia” muy avanzada -lo cual también podría decirse acerca de

\footnotetext{
${ }^{54}$ CASTORIADIS, La institución imaginaria de la sociedad, 446.

${ }^{55}$ CASTORIADIS, La institución imaginaria de la sociedad, 473.

${ }^{56}$ CASTORIADIS, La institución imaginaria de la sociedad, 446.

${ }^{57}$ LAPLANCHE y PONTALIS, Fantasía originaria, fantasía de los orígenes, origen de la fantasía.

${ }^{58}$ CASTORIADIS, La institución imaginaria de la sociedad, 448.

${ }^{59}$ CASTORIADIS, La institución imaginaria de la sociedad, 448.

${ }^{60}$ LAPLANCHE y PONTALIS, Fantasía originaria, fantasía de los orígenes, origen de la fantasía, 89.
} 
los materiales de los sueños-, el rasgo definitorio de las mismas reside en su modo de organización, que es "la modalidad fundamental de la indistinción del sujeto y el nosujeto"61. Es posible comprender esto si se tiene en cuenta que "la fantasía puede tomar de la "experiencia” todo lo que se quiera salvo, una vez más, lo que la experiencia no puede darle porque no lo posee" ${ }^{6}$, es decir, ese modo de organización originario, pleno de sentido primario para el sujeto, que sólo puede ser puesto por la psique. Por esto las fantasías portan la "huella del estado originario de la psique[,] en la medida en que ésta tiende a coincidir con la escena total, pues su estado originario, la representación 'primaria', es 'escena total'”63. Desde aquí también se puede volver sobre la cuestión de la capacidad representacional de la psique. Como señalan Laplanche y Pontalis, "lejos de ver en las pulsiones el fundamento de la fantasía, [Freud] hace depender la actividad instintual de estructuras fantasmáticas previas" ${ }^{64}$. Castoriadis se servirá de esta afirmación para dejar en claro que la capacidad imaginativa de la psique, lo que para él se corresponde con la imaginación radical del sujeto singular,

preexiste y preside toda organización de la pulsión, incluso la más primitiva, que es condición de acceso de esta última a la existencia psíquica, que es en un fondo de representación originaria [Ur-Vorstellung] donde la pulsión toma, 'en el punto de partida mismo', su 'delegación por representación', su Vorstellungsrepräsentant ${ }^{65}$.

El mencionado "estado de reposo psíquico" consistiría entonces, más específicamente, en "un fondo de representación originaria”, flujo incesante que brota sin necesidad de "estímulo exterior" alguno (o incluso "interior", ya que antecede a la misma pulsión) y que es creado por la imaginación radical, y en el marco del cual la pulsión deberá encontrar una delegación que la represente ante la psique.

En este punto, Castoriadis se separa de las conclusiones a las que arriban Laplanche y Pontalis, quienes remiten el surgimiento de las fantasías a la aparición de los comportamientos autoeróticos ${ }^{66}$. Para Castoriadis, en cambio, el autoerotismo refiere más bien a "una formación secundaria" ${ }^{67}$, en la medida en que -al menos en el modo en que esta noción es presentada en Tres ensayos de teoría sexual- esta organización sexual de la pulsión presupone la pérdida del objeto y la correlativa capacidad del infans de "formarse la representación global de la persona a quien pertenecía el órgano que le dispensaba

\footnotetext{
${ }^{61}$ CASTORIADIS, La institución imaginaria de la sociedad, 448.

${ }^{62}$ CASTORIADIS, La institución imaginaria de la sociedad, 448.

${ }^{63}$ CASTORIADIS, La institución imaginaria de la sociedad, 448.

${ }^{64}$ LAPLANCHE y PONTALIS, Fantasía originaria, fantasía de los orígenes, origen de la fantasía, 79.

${ }^{65}$ CASTORIADIS, La institución imaginaria de la sociedad, 449.

${ }^{66}$ LAPLANCHE y PONTALIS, Fantasía originaria, fantasía de los orígenes, origen de la fantasía, 85.

${ }^{67}$ CASTORIADIS, La institución imaginaria de la sociedad, 450.
} 
satisfacción” ${ }^{68}$. En su lugar, Castoriadis remite el fantaseo a la teoría del narcisismo, identificándola con "lo que podríamos llamar autoerotismo originario o narcisismo primario"69, o más precisamente, como una suerte de "autismo"70. En la medida en que para el infans el pecho materno no se llega a distinguir del cuerpo propio y es por tanto tomado como una parte indivisa de sí mismo, el objeto de las investiduras libidinales originarias es "el yo-ello todavía indiferenciado" 71 . Por tanto, la distribución de la carga libidinal recae enteramente en esta unidad indiferenciada, libido de "autocarga" que permanece "inmediatamente junto a sí y en sî" ". Siguiendo con su línea interpretativa, Castoriadis sostendrá que este modo de distribución narcisista "es necesariamente también representación", la cual se corresponde con el mencionado rasgo de indistinción de las fantasías originarias: “el sujeto psíquico originario es esa 'fantasía' primordial, a la vez representación y carga de un Sí mismo que lo es Todo”73. El autor conceptualizará esta representación primordial a partir de la noción de mónada psíquica, entendida como un proto-estado clausurado sobre sí mismo cuya característica central, tal como se desprende de lo anterior, es la indistinción entre sujeto y no-sujeto ${ }^{74}$. Castoriadis también describe este estado como un flujo indisociable e indiviso en el que resulta imposible distinguir al afecto que emerge de la representación de sí mismo que suscita y de la intención de mantenerse en tal estado, lo cual constituye la manifestación más plena de la imaginación radical. De aquí se deriva la omnipotencia de la psique en tanto capacidad de proveerse de la representación que le suscitará placer incluso antes de que surja la tendencia que busca retornar a tal estado. El despliegue inmediato de tales tres elementos -representación,

\footnotetext{
${ }^{68}$ FREUD, Tres ensayos de teoría sexual, 202.

${ }^{69}$ CASTORIADIS, La institución imaginaria de la sociedad, 450. En una entrevista con Urribarri, Castoriadis reconoce que la noción de narcisismo siempre le resultó problemática, en la medida en que implica cierta diferenciación entre sujeto y objeto que no resultaría adecuada para describir este estado primigenio. Véase URRIBARRI, Cornelius Castoriadis: subjetividad e históricosocial.

${ }^{70}$ CASTORIADIS, La institución imaginaria de la sociedad, 460-461. CASTORIADIS, Figuras de lo pensable, 184.
}

${ }^{71}$ FREUD, Esquema del psicoanálisis, 147.

72 CASTORIADIS, La institución imaginaria de la sociedad, 460.

${ }^{73}$ CASTORIADIS, La institución imaginaria de la sociedad, 450.

${ }^{74}$ La noción de mónada psíquica ha sido objeto de diversas críticas y reformulaciones desde la filosofía, el psicoanálisis y la teoría social. Algunas de las discusiones más relevantes en: HABERMAS, Excurso sobre C. Castoriadis: "La institución imaginaria". WHITEBOOK, Intersubjectivity and the Monadic Core of the Psyche: Habermas and Castoriadis on the Unconscious. GAUCHET, Redefining the Unconscious. SMITH, Re-imagining Castoriadis's Psychic Monad. STAVRAKAKIS, Antinomies of Creativity: Lacan and Castoriadis on Social Construction and the Political, 49-60. ELLIOTT, Subjectivity, Culture, Autonomy: Cornelius Castoriadis, 85-97. STEPHANATOS, Repenser la psyché et la subjectivité avec Castoriadis. PECHRIGGL, Psyché-soma ou monade psychique : difficile liberté entre institution imaginaire et incorporation culturelle. CIARAMELLI, Creación humana y paradoja de lo originario. BLEICHMAR, Fecundidad de la herencia de Castoriadis. FERNÁNDEZ, Las lógicas colectivas: imaginarios, cuerpos y multiplicidades, 125-128. 
afecto e intención- se organiza a partir de la "figura figurante" o esquema "todo = símismo", o más precisamente, "sí-mismo = todo = placer = sentido"75, el cual constituirá, incluso en etapas psicogenéticas posteriores, la matriz del sentido para la psique ${ }^{76}$. Como se puntualizará a continuación, es posible aprehender esta actividad representacional como un primer estrato en la constitución psíquica.

\section{Los estratos psíquicos. Un abordaje de la actividad representacional como puesta en forma y puesta en relación}

La anterior revisión de la actividad psíquica a partir de la perspectiva de Castoriadis permite iluminar particularmente lo que es pertinente a su orden representacional. Es repensando esta cuestión, presente en el pensamiento de Freud aunque en gran medida negada, como el autor llega a concebir en el seno de la psique una capacidad de presentación o de puesta en forma por parte de la subjetividad humana, lo cual da cuenta de una de las dimensiones más radicales de su imaginación. Esta capacidad, a su vez, no permanece inmutable durante el decurso de la vida psíquica, sino que "sufre un desarrollo inmenso en y por la historia del sujeto"77. Así como desde los distintos "puntos de vista" que propone el psicoanálisis puede indagarse el proceso en virtud del cual emergen nuevos "sistemas" o "instancias psíquicas", nuevos "conflictos" entre las mismas, o nuevos "modos de funcionamiento" o "principios" regulatorios de la actividad psíquica, un abordaje del orden cualitativa como el que aquí interesa también permite distinguir entre los diferentes procesos pertinentes a la actividad representacional de la psique. Para describirlos, en ocasiones Castoriadis se sirve de la propia noción de instancia psíquica, aunque mostrándose crítico de ciertas connotaciones substancialistas, cartesianas o estructuralistas en ocasiones asociadas a su utilización ${ }^{78}$. Sin embargo, destaca que esta noción permite comprender la relativa independencia que guardan entre sí los procesos psíquicos, tanto en su operatoria como en la persecución de sus propias finalidades ${ }^{79}$. Es así como propone pensar esta multiplicidad de procesos como una de las especificidades de la psique humana, pertinente a su "dimensión vertical” en tanto "estratificación psíquica”, que responde a la "historicidad del ser humano" como proceso de socialización

\footnotetext{
75 CASTORIADIS, La institución imaginaria de la sociedad, 470. URRIBARRI, Castoriadis: the Radical Imagination and the Post-Lacanian Unconscious, 45.

${ }^{76}$ CASTORIADIS, Figuras de lo pensable, 184.

77 CASTORIADIS, La institución imaginaria de la sociedad, 443.

${ }^{78}$ Véase CASTORIADIS, La institución imaginaria de la sociedad, 431-441. CASTORIADIS, Sujeto y Verdad en el mundo histórico-social, 89-92. CASTORIADIS, El estado del sujeto hoy, 128-134.

${ }^{79}$ CASTORIADIS, El estado del sujeto hoy, 120.
} 
indisociablemente sociogenético y psicogenético ${ }^{80}$. Centrándose en esta última vertiente, Castoriadis $^{81}$ explica que la mónada inicial descrita en la sección anterior sufre una ruptura a partir de la emergencia del displacer en su mundo psíquico, producido por la ausencia del objeto. El posterior reconocimiento de que su pertenencia a otro sujeto -la madrellevará al establecimiento de una fase triádica cuyo esquema organiza relaciones en tres términos: sujeto - objeto - otro. La omnipotencia que se atribuye a ese primer otro, por su potestad de regular la presencia o la ausencia del objeto -y por tanto, la vivencia de placer o de displacer en el infans-, sólo podrá ser destituida al remitirse a la institución de la sociedad como fuente de la significación, lo cual explica el sentido profundo del complejo de Edipo en el proceso de socialización ${ }^{82}$. La particularidad de esta historicidad humana radica en que estos procesos psíquicos pervivirán sin cancelaciones en la conformación estratificada de la subjetividad, ya que "las etapas ulteriores no anulan las etapas anteriores ni las integran armoniosa y orgánicamente" ${ }^{83}$. Se establece así una relación de superficialidad-profundidad inscripta en la psique misma que diferencia la concepción de Castoriadis de otros enfoques psicoanalíticos. Desde esta perspectiva también resulta posible conjeturar la existencia de un "peso diferencial” entre los sentidos pretéritos y contemporáneos instituidos en la subjetividad ${ }^{84}$.

De este modo, la noción de instancia o estrato psíquico resulta remitida a la perspectiva ontológica de Castoriadis, en la que se establece como pertinente a la región del para sí (o selff) a todo aquello que se caracteriza por "ser fin de sí-mismo" e instituir un mundo propio de sentido (Eigenwelt) ${ }^{85}$. Es así como el autor afirma que "cada instancia, cada tipo de proceso, es para si" " plantea su propia autofinalidad en base a la cual instituye un mundo propio de sentido que se encuentra en una clausura operacional, lo cual significa que exige la elaboración según sus propias directrices de todo lo que se (le) presente. Esta cuestión también ha sido conceptualizada por Aulagnier ${ }^{87}$ al definir a la actividad de representación de la psique

${ }^{80}$ CASTORIADIS, Sujeto y Verdad en el mundo histórico-social, 89. Véase también: CASTORIADIS, El estado del sujeto hoy, 131-132. CASTORIADIS, La institución imaginaria de la sociedad, 469.

${ }^{81}$ Véase CASTORIADIS, La institución imaginaria de la sociedad, 461-494. CASTORIADIS, Figuras de lo pensable, 237-255.

82 Para una exposición más detallada de este proceso psicogenético y sus consecuencias desde una perspectiva psicoanalítica, véase: URRIBARRI, La psique: imaginación e historia. Las ideas psicoanalíticas de Cornelius Castoriadis. FRANCO, Magma: Cornelius Castoriadis: psicoanálisis, filosofía, política.

${ }^{83}$ CASTORIADIS, Sujeto y Verdad en el mundo histórico-social, 91.

${ }^{84}$ FERME et al., Sobre la constitución de la subjetividad: coexistencia de los sentidos, la afectividad y la reflexión.

${ }^{85}$ CASTORIADIS, El estado del sujeto hoy, 123.

${ }^{86}$ CASTORIADIS, Sujeto y Verdad en el mundo histórico-social, 91.

${ }^{87} \mathrm{Al}$ respecto del vínculo entre Aulagnier y Castoriadis, y su importancia para la introducción de este último en el psicoanálisis, véase DOSSE, Castoriadis: una vida, 141-160. Sobre los distintos puntos de complementariedad y convergencia entre sus obras, véase: STEPHANATOS, Repenser la psyché et la 
como una "metabolización": trabajo cuya meta reside en la conversión de un elemento heterogéneo a un proceso psíquico en un material homogéneo a sus propias características $^{88}$. Si bien se trata de un concepto tomado de la biología, la autora lo utiliza para caracterizar el trabajo psíquico, en el que lo metabolizado no es un elemento físico sino "información”. Con cada tipo de proceso psíquico que emerge se inauguran, según Castoriadis, "objetos nuevos correlativos a esta instancia, valuaciones y afectos específicos, apeticiones y un tipo de sentido nuevo y específico", o, dicho con otras palabras, "un nuevo modo del representar, un modo del desear, un modo del ser-afectado, que son específicos" ${ }^{9}$. Desde aquí puede comenzar a pensarse la consistencia del mundo propio de sentido de cada estrato atendiendo a una dimensión más cualitativa, que da cuenta del entramado de representaciones, afectos e intencionalidades que los mismos instituyen.

Un elemento particularmente llamativo de esta propuesta es la idea de que cada estrato psíquico instituye "un tipo de sentido" que es "nuevo" respecto de aquellos previamente sedimentados y "específico" del proceso en cuestión. Según Castoriadis, la especificidad en el sentido instaurado por cada proceso psíquico consiste en "la inserción de representaciones en tipos de relación nuevos (que los modifican evidentemente ellas mismas), pues las matrices de equivalencia y de pertenencia son otras" ${ }^{90}$. En una dirección similar, Aulagnier plantea que los elementos de información heterogéneos a los que cada proceso de metabolización se enfrenta son sometidos al "esquema" o "modelo relacional" que caracteriza a cada proceso, de manera que las representaciones así producidas resulten homogéneas a la estructura de la propia instancia representante ${ }^{91}$. Lo que hay que desentrañar para comprender la consistencia de cada estrato es, en palabras de Castoriadis, la operatoria de estas "matrices de equivalencia y de pertenencia", que se presentan como modos específicos de organización y reorganización del material psíquico y que coexisten en una sedimentación sin cancelaciones. Al mismo tiempo, la mención de "la inserción de representaciones en tipos de relación nuevos" permite pensar que cada proceso o estrato no sólo produce representaciones de acuerdo con su matriz, sino que también reanuda según sus propias características el sentido instituido por los demás estratos. Es en este sentido que Aulagnier ${ }^{92}$ afirma que las representaciones producidas por uno de los modos de metabolización resultan, para los demás, tan heterogéneas y extrañas como los elementos provenientes del espacio exterior a la psique. Pero también cabe señalar que, cuando se trata del mundo psíquico, esta clausura operacional adopta un

subjectivité avec Castoriadis. URRIBARRI, La psique: imaginación e historia. Las ideas psicoanaliticas de Cornelius Castoriadis. FRANCO, Magma: Cornelius Castoriadis: psicoanálisis, filosofía, política, 161-174.

${ }^{88}$ AULAGNIER, La violencia de la interpretación: del pictograma al enunciado, 23-24.

${ }^{89}$ CASTORIADIS, Sujeto y Verdad en el mundo histórico-social, 91.

${ }^{90}$ CASTORIADIS, Sujeto y Verdad en el mundo histórico-social, 91.

${ }^{91}$ AULAGNIER, La violencia de la interpretación: del pictograma al enunciado, 25-26.

${ }^{92}$ AULAGNIER, La violencia de la interpretación: del pictograma al enunciado, 25. 
carácter peculiar: "estas instancias no son pura exterioridad unas con respecto a otras, [sino que, por el contrario,] se tienen en cuenta unas a otras"93. De otra manera, sería imposible que un proceso censurara a otro. Desde aquí también puede pensarse las formaciones de compromiso o los procesos sublimatorios como un solapamiento de matrices de sentido.

Si bien Castoriadis no profundiza en la comprensión de los estratos psíquicos como matrices de sentido, el autor aborda esta cuestión a un nivel más general, en el marco de una exposición centrada en la comprensión del vínculo entre la “información” y las características del para sí. De manera que, tanto al respecto de las instancias psíquicas como de cualquiera de los otros niveles del para sí, puede sostenerse que la información o el sentido no se encuentran disponible, listo para ser tomado, del ambiente que le circunda. Siempre que haya información la habrá para alguien, es decir, sólo es información desde y para el punto de vista de un para sí. De manera que lo que se requiere para que un elemento adquiera tal estatuto es, justamente, de un trabajo de in-formación, es decir, de ser formado, presentado, organizado por y para "alguien": lo que existe exteriormente al mundo propio de sentido "no se convierte en algo sino al estar formada (in-formada) por el para sí considerado (...). La información es creada por un 'sujeto', y evidentemente a su manera"94. A este mismo nivel se ubicaría, específicamente en el terreno psíquico, el "trabajo creador" de la psique frente a la pulsión anteriormente abordados, así como también el mencionado concepto de "metabolización” de Aulagnier. Al nivel del para sí, Castoriadis identifica una serie de "presupuestos" necesarios para que adquiera un estatuto de "información" cualquier simple "ocurrencia" (en tanto "suceso casual”): esta última necesariamente “(a) debe ser 'captada' y (b) transformada en algo para el 'sujeto', y luego, (c) entrar en una matriz (un múltiplo ultracompleto de matrices) de significancia” ${ }^{95}$. Esto quiere decir que todo lo que es presentado por y para el para sí no sólo (a) debe poder ser captado por éste y (b) dotado de una forma adecuada por la capacidad representativa del mismo -requisitos casi evidentes en el marco de la propuesta del autor- sino que además (c) deberá ser "puesto en relación”, es decir que debe ser involucrado en una "matriz de significancia" gracias a la cual la forma puesta adquiera un sentido o significancia. Es por esto que Castoriadis señala que "no hay información más que siendo dada una 'base' para la cual toma sentido en tanto información” ${ }^{96}$. El mundo propio de todo para sí, por consiguiente, no se encuentra compuesto por imágenes sin solución de continuidad, sino que está atravesado por “matrices” de sentido que las ponen en relación entre sí. En esta dirección puede pensarse a la autofinalidad del para sícomo la matriz que en última instancia enlaza a las representaciones y a partir de la cual además se

\footnotetext{
${ }^{93}$ CASTORIADIS, Sujeto y Verdad en el mundo histórico-social, 91.

${ }^{94}$ CASTORIADIS, El estado del sujeto hoy, 124.

${ }^{95}$ CASTORIADIS, Sujeto y Verdad en el mundo histórico-social, 63.

${ }^{96}$ CASTORIADIS, Sujeto y Verdad en el mundo histórico-social, 64.
} 
despliegan las otras dos dimensiones que componen un mundo propio: una valoración o valuación afectiva de acuerdo con el aporte que lo representado realice en miras de la autofinalidad y, a partir de esta demarcación, una intencionalidad al respecto, pudiendo ser, en su estado de menor elaboración, la atracción o la evitación ${ }^{97}$. Tal como puntualiza Aulagnier, en el terreno psíquico el acto de representación es siempre coextenso a un acto de investidura que responde a la tendencia psíquica de preservar o reencontrar el placer ${ }^{98}$. Cabe aclarar que los tres "presupuestos" de la información descompuestos por Castoriadis no deben ser considerados como momentos diferenciados cronológicamente -incluso a pesar de que el autor intercale la palabra "luego" entre los presupuestos (b) y (c)- sino que más bien operan en una "solidaridad lógica y efectiva" que sólo puede ser deslindada en un plano teórico ${ }^{99}$.

En base a estos lineamientos, Castoriadis sostendrá que se "construye un dispositivo para el cual hay información (...) un dispositivo para el cual todo lo que es recogido/presentado está dotado de una forma y al mismo tiempo puesto en relación” ${ }^{100}$. De modo que ambas operaciones, poner/dotar de forma y poner en relación, resultan inseparables e intervienen en la constitución de toda información por parte de la capacidad imaginativa del para sí. Como se dijo, sólo analíticamente resulta posible sostener una separación entre estos dos momentos, ya que presentar supone a la vez organizar lo que fue dotado de una forma. La información no puede ser concebida de manera aislada, sino que siempre se encuentra vinculada a un "marco específico" que es finalmente el que la dota de tal carácter, haciéndola pertinente en tanto que "información” según aporte o no a la consecución de un fin o interés subjetivo. Dicho con otros términos, no puede hablarse de sentido allí donde los elementos se encuentran aislados entre sí. Es por esto que Castoriadis comprende que "nunca se trata (...) de la simple presentación de un elemento: esta presentación siempre tiene lugar en una red de relaciones, es decir, finalmente, en una red de categorías (lógicas)” ${ }^{101}$. Como indica Urribarri ${ }^{102}$ al respecto del trabajo psíquico, representar supone vincular diferentes elementos dentro de una forma o figura, es decir, dentro de una red de representaciones. En consecuencia, la "matriz de significancia" que interviene en la constitución de la información, e incluso las "matrices de equivalencia y de pertenencia” por las que Castoriadis explica el nuevo tipo de sentido inaugurado por cada estrato psíquico, pueden ser pensadas como una "red de relaciones" que trasciende en todas las direcciones a una información puntual y que al mismo tiempo -gracias a esto- la

\footnotetext{
97 Cf. CASTORIADIS, El estado del sujeto hoy, 124-125. CASTORIADIS, Hecho y por hacer. Pensar la imaginación, 305-306. CASTORIADIS, Sujeto y Verdad en el mundo histórico-social, 57-58.

${ }^{98}$ AULAGNIER, La violencia de la interpretación: del pictograma al enunciado, 28.

${ }^{99}$ CASTORIADIS, Sujeto y Verdad en el mundo histórico-social, 67.

${ }^{100}$ CASTORIADIS, Sujeto y Verdad en el mundo histórico-social, 64.

${ }^{101}$ CASTORIADIS, Sujeto y Verdad en el mundo histórico-social, 65.

${ }^{102}$ URRIBARRI, Castoriadis: the Radical Imagination and the Post-Lacanian Unconscious, 43.
} 
dota de sentido ${ }^{103}$. Son estas matrices las que otorgan un espesor cualitativo, o mejor, fenomenológico, al mundo de sentido propio del para sí, en la medida en que regulan el modo específico en que se entraman entre sí las representaciones, afectos e intencionalidades por él creadas.

Asimismo, en lo pertinente al psicoanálisis, Castoriadis ${ }^{104}$ propone revisar la distinción establecida por Aulagnier ${ }^{105}$ entre la "puesta en escena” y la "puesta en sentido", nociones que el primer autor considera equivalentes, respectivamente, a lo que en sus planteos son la puesta en forma y la puesta en relación. Para Aulagnier, la "puesta en escena" es correspondiente a la actividad de los procesos primarios de la psique y al fantaseo, mientras que la "puesta en sentido" define a los procesos secundarios y a las representaciones ideicas o enunciados del Yo, que se encuentran bajo la égida del discurso. Si bien Castoriadis califica a esta distinción como "esclarecedora y pertinente", señala que sin embargo no puede ser sostenida "hasta el final" ${ }^{106}$. Llevada a su extremo, esta distinción podría conducir a pensar que la capacidad de puesta en relación es un producto tardío en la constitución del sujeto, de manera que en la actividad representacional primaria no se establecerían relaciones. Pero para el autor resulta imposible concebir una puesta en forma que no involucre una mínima puesta en relación, y viceversa: "Nunca una imagen surge en tanto átomo, sin relación con otra cosa, y nunca una imagen puede tener cohesión en tanto imagen si no hay relación entre sus partes" ${ }^{107}$; y, simultáneamente, "el sentido tiene que estar apuntalado por una imagen -y por ende inscripto en las obras de la imaginación radical”" ${ }^{108}$. Por consiguiente, así como toda presentación supone una puesta en sentido en el marco del mundo propio al que se integra, todo proceso de pensamiento -en tanto vinculación de representaciones- requiere ineludiblemente de un soporte a partir de las "imágenes" o formas que pone en relación. Si se aplica esta idea sobre los procesos primarios, en los que según Aulagnier sólo corresponde reconocer una "puesta en escena”, puede observarse que la fantasía ya implica al menos un mínimo sentido y orienta de una manera específica aquello que es presentado. Como diría Castoriadis, la fantasía -que da cuenta de un "fondo representativo" en el sujeto como primer estrato de la subjetividadorganiza/dispone lo presentado en una "escena total” cuyo sentido reside en la indistinción entre sujeto y objeto ${ }^{109}$. De manera que la puesta en forma de esta representación ya presupone una puesta en relación de acuerdo a la matriz o esquema "unificador" del "todo = sí-mismo". De otro modo, habría que sostener que en la fantasía no hay ningún tipo de

\footnotetext{
${ }^{103}$ CASTORIADIS, Sujeto y Verdad en el mundo histórico-social, 65.

${ }^{104}$ CASTORIADIS, Sujeto y Verdad en el mundo histórico-social, 65-66.

${ }^{105}$ AULAGNIER, La violencia de la interpretación: del pictograma al enunciado.

${ }^{106}$ CASTORIADIS, Sujeto y Verdad en el mundo histórico-social, 65.

${ }^{107}$ CASTORIADIS, Sujeto y Verdad en el mundo histórico-social, 66.

${ }^{108}$ CASTORIADIS, Hecho y por hacer. Pensar la imaginación, 142.

${ }^{109}$ CASTORIADIS, La institución imaginaria de la sociedad, 470.
} 
organización, lo que equivaldría a afirmar que se trata de un heterogéneo completamente caótico -lo cual resulta contradictorio si se parte de la idea de que la representación se ubica en las antípodas de un absoluto "caos de impresiones internas y exteriores"110. Quitar el estatuto de "puesta en sentido" a la fantasía, además, llevaría a pensar que las primeras elaboraciones psíquicas no gozan de consistencia alguna, y se volvería así a la discusión acerca de la procedencia "real" de los elementos de los que se sirve la primera representación del sujeto y a la pasividad de la psique que tal concepción supone. Los estratos que emergerán posteriormente en el decurso psicogenético remodelarán esta matriz sin cancelarla, para así adecuar la actividad representacional al "exceso de información" que comportan los objetos de investidura"111, con el fin de mantener "cierta coherencia representativa" ${ }^{112}$ al interior del espacio psíquico. Así, el establecimiento de la fase triádica supone la introducción de un esquema relacional de tres términos que responde a la fórmula condicional del "sí... entonces..."113. De este modo, aunque la omnipotencia del pensamiento resulta ahora obstaculizada por el reconocimiento de un otro, se establece que todas sus acciones se encuentren referidas o son causadas por las acciones del propio sujeto. Como si se tratara de una suerte de "omnipotencia diferida", el infans comprende que realizando los actos correctos provocará la presencia del otro y así el reencuentro con el objeto, y dota de sentido la escena según esta lógica. Cuando el esquema del "si... entonces..." es remitido a la institución social y las causalidades pasan a estar fundamentadas en las significaciones colectivas -sean estas de orden religioso, mítico o científico-, el sujeto podrá adoptar los “encadenamientos reales-racionales" que explican y dotan de sentido lo que acontece ${ }^{114}$. Como se dijo previamente, el surgimiento de estos esquemas no supone la anulación de las representaciones, objetos, afectos e intencionalidades instauradas por los procesos preexistentes, sino que estos sentidos pervivirán en el seno de la subjetividad a la manera de, como sostiene Castoriadis parafraseando a Freud ${ }^{115}$, "capas superpuestas de lava”"116.

Recorriendo toda esta serie de cuestiones Castoriadis llega a la siguiente conclusión, que reúne los distintos puntos transitados en esta exposición:

no puede haber puesta en escena que no sea al mismo tiempo puesta en relación, es decir, puesta en sentido; que no puede haber presentificación que no sea al mismo tiempo organización, ni dato sensorial que no implique categorialidad. (...) Toda función imaginante del sujeto, toda

\footnotetext{
${ }^{110}$ CASTORIADIS, La institución imaginaria de la sociedad, 443.

${ }^{111}$ AULAGNIER, La violencia de la interpretación: del pictograma al enunciado, 31.

112 CASTORIADIS, Hecho y por hacer. Pensar la imaginación, 135.

${ }^{113}$ CASTORIADIS, La institución imaginaria de la sociedad, 479.

${ }^{114}$ CASTORIADIS, La institución imaginaria de la sociedad, 485.

${ }^{115}$ FREUD, Pulsiones y destinos de pulsión, 126.

116 CASTORIADIS, La institución imaginaria de la sociedad, 489.
} 
función presentificante es por este hecho y al mismo tiempo una función organizante, es decir, en un nivel tan elemental como se quiera, una función dadora de sentido ${ }^{117}$.

En esta cita se establece la final equivalencia entre categorías de gran importancia: organizar equivale a poner en relación y por lo tanto dotar de sentido una serie de elementos, lo cual necesariamente ya implica cierta categorialidad, aunque sea en un grado sumamente elemental; mientras que poner en escena o poner en forma es una actividad imaginante del sujeto que equivale a presentificar algo, lo que ya es pertinente incluso al nivel de lo sensorial. Finalmente se constata que presentificación y organización, aunque distinguibles analíticamente, no pueden operar por separado, ya que la potencia de la imaginación demuestra que se implican mutuamente en sus producciones.

\section{Consideraciones finales}

En el presente trabajo se propuso recuperar la reflexión filosófica y psicoanalítica de Castoriadis para profundizar en la comprensión de un aspecto poco abordados de la actividad psíquica: su dimensión representacional como capacidad de presentación y de puesta en sentido. La revisión de distintos puntos de la obra freudiana permite a Castoriadis postular que debe reconocerse la existencia de esta dimensión desde el albor mismo de la vida anímica, sin lo cual sería imposible introducir al terreno de la cualidad y de la representación psíquica aquello que se encuentra por fuera de la misma. Recuperando particularmente el problema de la manifestación de las pulsiones en el terreno psíquico, se evidencia el trabajo creador que la psique debe operar sobre los impulsos somáticos para dotarlos de un "delegado" representacional. La problematización de la actividad alucinatoria y la fantasía -ambas basadas en un modelo que supone la recreación o reproducción de una experiencia o percepción "real" en su origen- permitió caracterizar la actividad representacional inaugural, remitiéndola al "estado de reposo" que el propio Freud identifica al inicio de la vida psíquica y vinculándola con un modo de organización en el que resulta imposible la distinción entre sujeto y no-sujeto. Con la alteración de esta capacidad representacional durante el devenir psicogenético, emergen nuevas instancias o estratos psíquicos en virtud de los cuales se instituyen en la subjetividad modos específicos de puesta en forma o presentación y esquemas relacionales o matrices de sentido particulares. Esto permite reconstruir el espesor cualitativo de los distintos modos de organización de la actividad representacional, entendido como un entramado particular de sentidos, objetos, afectos e intencionalidades organizados a partir de esquemas específicos.

${ }^{117}$ CASTORIADIS, Sujeto y Verdad en el mundo histórico-social, 67. Las cursivas son nuestras. 
Por último, cabe recuperar uno de los puntos del texto inédito "El psicoanálisis: situación y límites”, publicado póstumamente, en el que Castoriadis establece una visión de conjunto y una síntesis de su reflexión en torno a la teoría y la práctica psicoanalíticas. Al abordar la cuestión de la metapsicología, señala que las elucidaciones de Freud se encontrarían fundadas en una "decisión teórica” según la cual

el mundo psíquico no está constituido solamente de sentido, se conforma a través de (...) una creación de sentido según una organización dada, o sea, algunos rasgos de estructura y de funcionamiento constantes, permanentes o duraderos, algunas determinaciones y leyes ${ }^{118}$.

Se puede pensar que es la decisión de privilegiar particularmente esta última serie de elementos, pertinentes a una dimensión estructural y lógica de la psique, la que llevó a la metapsicología freudiana a desatender, por momentos, la dimensión imaginaria y poiética de los fenómenos psíquicos. Como se pretendió mostrar en el presente artículo, quizás uno de los principales aportes de la perspectiva de Castoriadis acerca de la dimensión representacional de la psique resida en brindar elementos para comenzar a pensar una metapsicología que, a la vez que atienda a los rasgos estructurales del psiquismo, reintegre a la dimensión del sentido en la comprensión de su funcionamiento. El valor de la noción de estrato psíquico reside en captar la articulación entre estas dos dimensiones, es decir, el modo en que el flujo instituyente de la imaginación resulta encausado en distintas organizaciones parciales que surgen en el transcurso de la historia psicogenética y que dotan de consistencia y estabilidad a la actividad representacional de la psique.

\section{Referencias}

ADAMS, S. Castoriadis and autopoiesis. Thesis Eleven, n. 88, p. 76-91, feb. 2007. Disponible en: http://the.sagepub.com/content/88/1/76. Acceso en: 15 jun. 2020.

AUlAgnier, P. La Violencia de la interpretación. Del pictograma al enunciado. Buenos Aires: Amorrortu, 2010.

BLEICHMAR, S. Fecundidad de la herencia de Castoriadis. En: Franco, Y.; Freire, H.; Loreti, M. (Coords.). Insignificancia y autonomía. Debates a partir de Cornelius Castoriadis. Buenos Aires: Biblos, 2007.

CASTORIADIS, C. El estado del sujeto hoy. En: Castoriadis, C. El psicoanálisis, proyecto y elucidación. Buenos Aires: Nueva Visión, 1998.

${ }^{118}$ CASTORIADIS, Figuras de lo pensable, 225. 
CASTORIADIS, C. Figuras de lo pensable. Buenos Aires: Fondo de Cultura Económica, 2001.

CASTORIADIS, C. Hecho y por hacer. Pensar la imaginación. Buenos Aires: Eudeba, 1998.

CASTORIADIS, C. La institución imaginaria de la sociedad. Buenos Aires: Tusquets, 2013.

CASTORIADIS, C. Lógica, imaginación, reflexión. En: Dorey, R. (Comp.). El inconciente y la ciencia. Buenos Aires: Amorrortu, 1993.

CASTORIADIS, C. Los dominios del hombre. Las encrucijadas del laberinto. Barcelona: Gedisa, 1998.

CASTORIADIS, C. Sujeto y Verdad en el mundo histórico social. Buenos Aires: Fondo de Cultura Económica, 2004.

CIARAMELLI, F. Creación humana y paradoja de lo originario. Archipiélago, n. 54, p. 5866, 2002.

DOSSE, F. Castoriadis: una vida. Buenos Aires: El cuenco de plata, 2018.

ELLIOTT, A. Subjectivity, Culture, Autonomy: Cornelius Castoriadis. En: Elliott, A. Critical Visions. New Directions in Social Theory. Lanham: Rowman \& Littlefield Publishers, 2003.

FERME, F.; MARISCAL, C.; LÓPEZ, N.; COUZO, D.; CASTRO, M. y ROSSO, G. Sobre la constitución de la subjetividad: coexistencia de los sentidos, la afectividad y la reflexión. En: Lewin, H.; Dallorso, N.; Di Virgilio, M. (Coords.). Recorridos en investigación II: Programa Reconocimiento Institucional de Investigaciones Convocatoria 2013-2015. Buenos Aires: Facultad de Ciencias Sociales, Universidad de Buenos Aires, 2008.

FERNÁNDEZ, A. M. Las lógicas colectivas: imaginarios, cuerpos y multiplicidades. Buenos Aires: Biblos, 2007.

FRANCO, Y. Magma: Cornelius Castoriadis: psicoanálisis, filosofía, política. Buenos Aires: Biblos, 2003.

FREUD, S. 23 ${ }^{\mathbf{a}}$ conferencia. Los caminos de la formación de síntoma. En: Freud, S. Obras Completas, Vol. XVI (1916-1917). Buenos Aires: Amorrortu, 2008.

FREUD, S. Esquema del psicoanálisis. En: Freud, S. Obras Completas, Vol. XXIII (19371939). Buenos Aires: Amorrortu, 2008.

FREUD, S. Formulaciones sobre los dos principios del acaecer psíquico. En: Freud, S. Obras Completas, Vol. XII (1911-1913). Buenos Aires: Amorrortu, 2008.

FREUD, S. Fragmentos de la correspondencia con Fliess. En: Freud, S. Obras Completas, Vol. I (1886-1899). Buenos Aires: Amorrortu, 2008. 
FREUD, S. Lo inconciente. En: Freud, S. Obras Completas, Vol. XIV (1914-1916). Buenos Aires: Amorrortu, 2008.

FREUD, S. Nota sobre el concepto de lo inconciente en psicoanálisis. En: Freud, S. Obras Completas, Vol. XII (1911-1913). Buenos Aires: Amorrortu, 2008.

FREUD, S. Pulsiones y destinos de pulsión. En: Freud, S. Obras Completas, Vol. XIV (1914-1916). Buenos Aires: Amorrortu, 2008.

FREUD, S. Tres ensayos de teoría sexual. En: Freud, S. Obras Completas, Vol. VII (19011905). Buenos Aires: Amorrortu, 2008.

GAUCHET, M. Redefining the Unconscious. Thesis Eleven, n. 71, p. 4-23, nov. 2002. Disponible en: http://the.sagepub.com/content/71/1/4. Acceso en: 15 jun. 2020.

GOURGOURIS, S. Philosophy and Sublimation. Thesis Eleven, n. 49, p. 31-43, may. 1997. Disponible en: http://the.sagepub.com/content/49/1/31. Acceso en: 15 jun. 2020.

HABERMAS, J. Excurso sobre C. Castoriadis: "La institución imaginaria”. En: Habermas, J. El discurso filosófico de la modernidad. Madrid: Taurus, 1993.

LAPLANCHE, J. La sublimación (Problemáticas III). Buenos Aires: Amorrortu, 2002.

LAPLANCHE, J. y PONTALIS, J.-B. Diccionario de psicoanálisis. Barcelona: Labor, 1993.

LAPLANCHE, J. y PONTALIS, J.-B. Fantasía originaria, fantasía de los orígenes, origen de la fantasía. Barcelona: Gedisa, 1986.

PECHRIGGL, A. Psyché-soma ou monade psychique: difficile liberté entre institution imaginaire et incorporation culturelle. En: Klimis, S.; Van Eynde, L. (Dirs.). Psyché: De la monade psychique au sujet autonome. Bruselas: Presses de l'Université Saint-Louis, 2007. Disponible en: https://books.openedition.org/pusl/827. Acceso en: 15 jun. 2020.

ROUDINESCO, E. y PLON, M. Diccionario de psicoanálisis. Buenos Aires: Paidós, 2008.

SMITH, K. E. Re-imagining Castoriadis's Psychic Monad. Thesis Eleven, n. 83, p. 5-14, nov. 2005. Disponible en: <http://the.sagepub.com/content/83/1/5>. Acceso en: 15 jun. 2020.

STAVRAKAKIS, Y. Antinomies of Creativity: Lacan and Castoriadis on Social Construction and the Political. En: Stavrakakis, Y. The Lacanian Left: Psychoanalysis, Theory, Politics. Edimburgo: Edinburgh University Press, 2007.

STEPHANATOS, G. Repenser la psyché et la subjectivité avec Castoriadis. En: Klimis, S.; Van Eynde, L. (Dirs.). Psyché: De la monade psychique au sujet autonome. Bruselas: Presses de l'Université Saint-Louis, 2007. Disponible en: https://books.openedition.org/pusl/839. Acceso en: 15 jun. 2020.

STRACHEY, J. Nota introductoria a "Pulsiones y destinos de pulsión”. En: Freud, S. Obras Completas, Vol. XIV (1914-1916). Buenos Aires: Amorrortu, 2008. 
URRIBARRI, F. Castoriadis: la sublimación extendida. Zona Erógena, Buenos Aires, n. 45, p. 53-58, 2000.

URRIBARRI, F. Castoriadis: the Radical Imagination and the Post-Lacanian Unconscious. Thesis Eleven, n. 71, p. 40-51, nov. 2002. Disponible en http://the.sagepub.com/content/71/1/40. Acceso en: 15 jun. 2020.

URRIBARRI, F. Cornelius Castoriadis: subjetividad e históricosocial. Zona Erógena, Buenos Aires, n. 15, p. 4-8, 1993.

URRIBARRI, F. La psique: imaginación e historia. Las ideas psicoanalíticas de Cornelius Castoriadis. Zona Erógena, Buenos Aires, n. 39, p. 43-50, 1998.

WHITEBOOK, J. Intersubjectivity and the Monadic Core of the Psyche: Habermas and Castoriadis on the Unconscious. Revue européenne des sciences sociales, Ginebra, t. 27, n. 86, p. 225-244, 1989. Disponible en: https://www.jstor.org/stable/40369870. Acceso en: 15 jun. 2020. 